\title{
APUNTES PARA UNA SEMIÓTICA DE LA DECONSTRUCCIÓN, SEGUIDOS DE UNA APLICACIÓN PRÁCTICA SOBRE EL CINE DE CIFESA
}

\author{
Josep Franco i Giner \\ Universitat de València
}

Nos gustaría aprovechar esta ocasión para acercar, todavía un poco más, esos dos campos teóricos, la semiótica y la deconstrucción, abriendo un nuevo horizonte en su posible aplicación, que ya no sería teórico. Es necesaria, a nuestro entender, esa aproximación de las posiciones más radicalmente enfrentadas que todavía dibujan este panorama doble: a la izquierda, pongamos por caso, Iteratividad, Semiótica, Estética de la Identidad, del reconocimiento, de la repetición; Platonismo, racionalismo, hegelianismo, marxismo; Comte, Hegel, Lukácks, Greimas, etcétera, y todo un plantel que ve en la repetición del signo la posibilidad de una ley general, que ve en la diversificación de fenómenos, pura apariencia y, por lo tanto, la posibilidad de reducción. Los propios estructuralistas, que ven en el hecho de que la repetición, la iteración, aumenta la coherencia de un texto, la posibilidad 
de las isotopías semánticas, el hecho de que debajo de lo aparente hay que buscar lo esencial de las estructuras profundas, etcétera. A la derecha, por ejemplo, Iterabilidad, Deconstrucción, Estética de la oposición, de la diferencia, de la innovación; un empirismo que excluye leyes generales; Hobbes, Hume, Derrida; el hecho de que la repetición de un texto produce siempre un nuevo sentido; que no es posible repetir un signo sin cambiar su identidad, que la repetición no aumenta la coherencia, sino que deshace el texto (semánticamente) y el contexto (pragmáticamente); que la iterabilidad produce una dispersión semántica, una diseminación, y que no permite, por lo tanto, que el signo permanezca idéntico a sí mismo, y que al mismo tiempo inaugura una paradoja: posibilita una pragmática contextual cambiante, abriendo así todos los contextos, etcétera.

Hay, en este panorama doble que nos sirve de marco para empezar nuestra exposición, un olvido. Se sigue situando a la repetición entre la identidad y la diferencia, entre la no-diferencia y la indiferencia, situando el problema, tanto de la semiótica como de la deconstrucción, en el hecho de la pertinencia de las clasificaciones, de las comparaciones. $\mathrm{Si}$ bien se reconoce que la deconstrucción es un correctivo al excesivo racionalismo de la semiótica, no se deja de querer incluirla en ésta. Y eso por una razón obvia: en ambos casos, al tratarse de dos teorías, será el $Y o$ quien las enuncie. En este Yo, pongamos por caso, podemos incluir, Mensaje; Indiferencia: género humano; todos los hombres somos iguales: Estado, feminismo, nacionalismo, marxismo, pero también, diferencia, individualidad, efecto real de la sociedad capitalista. Lengua, código, social; Circulación, Productividad, Transparencia; Hegel, Saussure, Hjelsmlev. Pensamiento, Razón, Identidad, Contexto, Reducción, Semiótica, Deconstrucción, Significado, Linealidad del Lenguaje, Achatamiento, Comunicación-Información, Nube, Respuesta.

Nuestra propuesta es abrir el se, el cuerpo, al texto, a la mirada e intentar una semiótica de la deconstrucción que no sólo tenga en cuenta los sentidos sino también los goces. Un espacio en el que podríamos incluir, la no-indiferencia, la responsabilidad por el otro y no el miedo del otro; afirmar, allí, la imposibilidad de usar balizas de protección. Blanco. Alteridad. Real. Palabra-escritura, no social. Intransitividad, Improductividad, Opacidad, Cuerpo, Materialidad. Nietzsche, Heidegger, Lévinas, Foucault, Barthes, y tantos otros; Pensamiento otro; No dialéctica, que siempre es reducción, significancia, función poética, volumen, ruido, grano. Polvo, Angustia, Deseo, Placer. Un espacio donde no quepa la certeza. 
En esas condiciones, ¿es posible, todavía, hablar de semiótica, de semántica, de semiología, de semiosis, de sentido exportable a otro lugar?, y ¿de qué color es éste último? ¿Es lícito seguir haciendo particiones? ¿Hasta cuándo hemos de permanecer dentro de la lógica de la no-diferencia, es decir, permanecer dentro de la dialéctica platoniana, de reducir la diferencia a contradicción para así poderla traer rápidamente y de un modo sospechosamente fácil a la identidad? Añadamos a continuación que aquella partición dialéctica es binaria, que avanza por exclusiones, por ramificaciones sucesivas, atravesando un haz de categorías antagónicas - ¿o deberíamos decir complementarias? - como la de lo Uno y lo Múltiple, lo Idéntico y lo que no lo es. ¿Duda alguien de que no es una cuestión de razón, de verdades, de sentidos, la que aquí se nos presenta, sino de poderes, de saberes? ¿Alguien duda de que de esta exposición lo único que podremos llevarnos a casa es nuestro propio cuerpo? Y aun así. ¿Quizás hay alguien que cree todavía que verdad y poder no son la misma cosa? Quien se sitúe en esas coordenadas se niega todavía a ver en la metafísica la historia de una arché, en nuestra historia de blancos, occidentales y machos, un olvido: la alteridad no ha sido pensada aún. Digámoslo de otro modo: sólo hemos pensado aquello que era posible pensar desde la posición del poder y del saber. Vivir distintamente, pensar simplemente, o pensar diversamente, no lo hemos hecho aún (Delooz, 1986).

Cuando decimos poder, bien que reconocemos, con cierta tradición, una verticalidad del falo, le asignamos, sin embargo, una eficacia de la horizontalidad: las estrategias se juegan a niveles actanciales, presenciales, de un modo microdiseminado: se encuentran allí donde hay un discurso, el que sea. Esta maquinaria no podría funcionar si no fuese por la diferencia de potencial - también en la anarquía, y a pesar de Lévinas, esto es, también del lugar de la alteridad, de otro modo si queremos- que ejerce sobre otro discurso: cualquiera que sea quien ejerza de yo en el momento que sea, siempre es más grande que el tú al cual se dirige. Si el yo se encuentra en estado acusativo ética y formalmente, y el tú en vocativo, también es verdad que en esa apelación, en esa petición de respuesta, todavía hay un sujeto, atrincherado ciertamente, malherido seguramente, pero el decir del cual quiere aún ser lo dicho, no el camino en que se dice. Esa técnica de las técnicas, que es el discurso, es el poder que genera saber: allí donde se producen las condiciones de posibilidad de nuestros decires, que no son partes de cierta estética, y también, sino que constituyen nuestra economía en el sentido más amplio del término, empezando por el propio cuerpo (Bodel, 1986), ese pedazo de desconocido que llevamos con nosotros, 
allí nos reconocemos como idénticos, entre la indiferencia y la diferencia, lejos de la no-indiferencia, protegidos por las balizas de protección de los géneros de las clasificaciones, al amparo de la razón. Moralizados y educados, hacemos lo imposible por parecernos a quienes construyen nuestros límites. Del discurso quedará perdido en el camino, en esa luz que se ilumina a sí misma, como el punto más claro del pie de una lámpara, a oscuras, olvidado, el sentido. Como aquel decir que se nos escapa de las manos, incluso antes de haberlo iniciado.

Subidos en la cresta, ya no sentimos ni el movimiento del agua. Todo está en calma. Todo, menos nuestro decir, nuestro poder decir no, que siempre se rebela contra aquel yo que quiere seguir diciendo: cogito ergo sum, que es donde estamos. ¿Donde podemos dejar el resentimiento del otro que quiere salir? ¿Resistirán nuestros héroes en sus trincheras, siguiendo el camino del sentido exportable, dejando la conciencia en su lugar de origen? ¿Saltará o no saltará sobre la razón -el sentido del que la tiene más larga- ese otro yo que nos mira con hambre de sentido y al que tememos en silencio desde la trinchera de la ley? ¿Podemos todavía aparcarlo, realizar otra partición? ¿Y si lo dejamos del lado del lenguaje, también? ¿Será, todavía, que podemos dejar algo al lado de algo? ¿Seremos aún capaces, y en nombre de qué color, de realizar otra exclusión? Cada vez que se asume un sentido, el sentido nasciturus de las condiciones de posibilidad de los discursos de nuestro presente, construimos otra pantalla de protección a nuestro alrededor y dejamos fuera el resto. Ya sé que si no fuese así nos anularíamos ahora mismo entre nosotros y ustedes, tan iguales como somos, sordos (Ponzio, 1982-1990).

Del sentido, pues, sólo oímos su ausencia. En este eco se construye, nos construimos. Sería lícito decir que es en el margen, en la bisagra de la partición donde podemos encontrar cierto sentido. Al cerrar la puerta chirría el grito de su decir: es ya un decir de óxido que se deshace cada vez que repetimos el movimiento, cada vez que ponemos en contacto la madera y el hierro, los muros de contención y al otro que tememos. De aquel grito oímos lejanamente su voz de oreja. Es, pues, de la ausencia del otro de donde podemos aprovechar nuestras serias series, las rocas en que se han convertido nuestros ojos de polvo. Por mucho que le quitemos el polvo a las palabras, seguirán pesando sus ecos (Schürmann, 1986).

También esta exposición está hecha de exclusiones de violencia, de violencia de exclusiones: recuerden sólo aquello que no diré, aquello de lo cual no hablaré, lo que no leerán; sólo así comenzarán a pensar. 
Cada vez que decimos yo, pues, nos estamos disculpando. A la pretensión de continuidad (de sentido), de traer el pasado a presencia y el futuro también, obsesión ontológica, podemos oponer la aparición de un aquí y ahora que dice de sí mismo, por sí mismo, sin que antes o después de ese hinc et hunc haya nada que justifique la serie. El acontecimiento, esto que estoy ofreciéndoles, por ejemplo, se explica por él mismo y no por referencia (negativa o no) a otro acontecimiento. Dicho de otro modo, el excedente de lo que tienen entre las manos no reenvía a ningún sitio; por eso permanece fuera del cómputo silábico que son nuestras clasificaciones, por eso es un ex-cedente. Querer aprehenderlo es inútil. Como lo es el hecho de querer asignarle una casilla de significado dentro de un espacio textual para tirar del sentido del texto. Y, si lo hacemos, reconozcamos al menos en el acto el acto de las trazas de la acción de dispositivos de poder: no verdades ni saberes blancos. Sólo poder. De los espacios textuales retendremos el peso de la retícula, la malla pesante salida del agua: el significado, si es tradición, también es traición al lenguaje: este debería ser libre. Y de hecho lo es, sólo que aquí intentaremos decir lo contrario. En este aquí se trabajan las condiciones del sentido, del texto. Nosotros preferiremos quedarnos fuera, es decir, en el con-texto, dejándonos atraer por el abismo de la ectopia argumental.

Es a través del juego dialéctico de replegarse sobre sí misma la contradicción como la partición se muestra en sucesivas síntesis, consolidando la subjetividad que quiere conservarse idéntica a ella misma, garantizando, así, la continuidad y el retorno a sí misma. Es el mecanismo, la dialéctica, según el cual la Alteridad es asumida y reducida a la Identidad. Un artefacto de simplificación del mundo, pero ninguna trascendencia, sin embargo. De ahí que no aceptemos el análisis semiótico si no es haciendo incursiones en lo político, como han hecho - hacen en sus textos aún- Roland Barthes (Barthes, 1973-1987) y Michel Foucault (Foucault, 1954-1984b), por ejemplo, por mencionar la sección transversal de estos decires.

No hemos de equivocar operaciones artificiosas por fundamentos ontológicos, ni creer que el pensamiento se corresponde con la realidad, ni que las categorías son la estructura invisible del mundo. Ya no es posible asignar movimientos ontológicamente fundados ni teleológicos, sino sólo, y con fortuna, relaciones de fuerza en continua transformación. Si la semiótica busca el objeto del texto, lo perderá en el intento. Nos ocurrirá como cuando nos queremos desembarazar de Hegel: siempre lo encontramos en otro sitio y cambiado de cara, 
perdido para nosotros y presente (recuerden que aparecía en las series semiótica y del yo). En lugar de esa tentativa binaria de síntesis, creemos que es más efectiva, para una lectura de la Historia, considerar a ésta una repetición: así se expresa el análisis de las particiones: deja más pesada la arena que moja, no se deja reducir a polvo invisible por las nubes. No hay aquí, como en el caso de la dialéctica, ninguna pretensión de totalidad, de reducción, sólo una explícita voluntad de poder efectivo, puntual, presente, en acción. Así se desarrolla, según nuestras sospechas, la Historia, a golpe de razones que son expresión de fuerza. Así también, el sentido que queremos asignarle a un enunciado, un hecho, un texto, un discurso, cualquiera que sea su forma, no será un sentido en relación con otro sentido, sino a la condición de posibilidad de sentido que tengamos. Cada vez que abrimos la caja de Pandora nos asustamos. ¿Qué es lo que encontramos? ¿Quizás una bestia macrofísica central que ejerce su poder desde arriba? Cierto, no. Aquel capital, la verticalidad del cual nadie niega, tiene cuerpecitos adheridos reticularmente que le incitan y construyen. No podemos, honestamente, seguir apelando a aquella única mano negra que nos vampiriza. En cada acción nuestra se ejerce un saber y un poder, microfísica del poder, que va dándole comida al gran otro. A ese que nos mira como lo miramos, invisible. Está en plena ascendencia. Cada vez que lo nombramos, lo volvemos a despertar de su posible letargo, que no conoce.

Para explicar relaciones reales y concretas, ya no será necesario recurrir a conceptos gigantescos tales como burguesía y capitalismo, sin perderlos aún de vista. Bien que nos desembaracemos un poco de su presencia persistente, no quiere decir que no sepamos hacia dónde miramos. Mecanismos infinitesimales más precisos y preciosos son los que dan lugar a la efectividad última de las relaciones. Se trataría más bien de una elección de método, más que de la pretensión de negar la existencia del vampiro. Alrededor de él, haciéndole de sombras y carencias, se reúne toda una serie ilimitada de estrategias. Miremos, pues, debajo de su capa en lugar de a sus ojos, que ya conocemos.

No es posible explicar, pues, el poder, el sentido, la historia, desde ningún centro ni a partir de él, dado que es el propio centro la condición de su posibilidad, su efecto y su causa. Se trataría más bien de observarlos siguiendo un movimiento centrípeto, desde los márgenes hacia el centro, en lugar de centrífugo, de éste hacia las exclusiones, según el proceso de las enanas blancas convertidas finalmente en agujeros negros. Podríamos empezar a encontrar sentido en esas microre- 
laciones personales, sean a nivel privado o público, comenzando la disolución de la diferencia, de esta diferencia, por ejemplo, y dejando paso a la no-indiferencia que reclama su espacio, no en el juego que va de la identidad a la máxima diferencia, del género humano hasta aquel individuo singular, sino abriendo el espacio dircursivo, sus condiciones de posibilidad, a ese otro que reclama su sitio.

Haría falta una historia de los gestos, una historia de los miedos, como el que demuestra Occidente hacia el otro, no por el otro según una aplastante lógica: temer al otro es condición necesaria y suficiente para que la conciencia esté tranquila y se construya el nosotros. Desde este lugar es desde donde nos hemos hecho, desde el miedo a la diseminación; la tentativa reiterada de la reducción a la Identidad; la angustia que produce no tener un sentido, no tener una ciencia, la semiótica, que explique su pertinencia, su objeto reducido a nada, controlada, clasificado, con los márgenes precisados hasta el más mínimo detalle. El objeto y su ciencia se ríen de nosotros con un estrépito tal, que nos ciega los oídos con los cuales pretendemos su escucha.

¿Qué le ocurriría a este centro blanco con la llegada masiva de otros centros -o con la voluntad de centros-, desplazados, que no sean blancos? Esta aportación quería plantear la necesidad de destruir rápidamente la posibilidad de tener que plantearse aún esta pregunta. Eliminando la pretensión de sentido. Cada vez que creemos ver en algún signo, una señal, o un índice, o un símbolo, un sentido, cada vez que lo construimos, que creemos que lo estamos construyendo, cada vez que nos convertimos en interpretantes, le quitamos el polvo a las palabras. Las nubes, los paraguas sociales, y el lenguaje sería uno de los más vistosos (con agujeros incluidos), sólo nos sirven para pedir perdón. Pero, ¿a quiénes y por qué? Al otro que nos mira, que lo vemos, que sabe que lo estamos mirando. Una semiótica de la deconstrucción, ¿para cuándo? Sólo es posible, y en voz baja, decir de uno mismo el trozo que el otro deja desvelarse de sí mismo. Sólo sería posible una moral, una ética, una verdad, un sentido, de uno mismo. Ocurre, sin embargo, que ese yo que quiere decir es ya un yo que se muestra como la verdad que quiere decir: muy poco verdadera. No se trataría de decir un yo más alto que otro, sino más bien de reconocerse esos yo como algo moriturus, cuestionados entre ellos y al mismo tiempo, sujetados a falsas tablas, situados sobre un suelo móvil, poco fiable, sin convicción posible. Y, evidentemente, repitámoslo, moriturus, sin futuro posible. Sólo desde el aquí y ahora, desde el presente, sería posible decir aún, y es tan breve ese aún que casi se te van las ganas de empezar. El 
curso de la Historia sólo acepta valoraciones a posteriori y cada una es su propio patrón. Padre patrón que subjetiviza el trazo.

Si tuviésemos que concluir, apostaríamos por el callar, ese no repetido hasta la saciedad desde los lugares más fríos. Aquí, caldeados por el género que nos reúne, sólo podemos apelar al silencio. Lo diremos una vez más, la última: la semiótica, si la vemos como condición de posibilidad de la fuerza de exclusión, como el panopticon que construye a los ciegos sabidos mirados, será nuestro lugar de partida, no para volver a ella, no para entresacar de sus profundidades ningún sentido exportable, más autorizado, sino para negar su condición de posibilidad, para cuestionarla hasta el límite, hasta la muerte. Nuestra lucidez nos la metemos en ese lugar privado que tanto nos estimamos, ustedes y nosotros, ellas y ellos: ese lugar se llama deseo.

\section{CIFESA: ENTRE EL MITO Y EL ONANISTRÓN CYBURGUÉS}

Los hombres siempre estamos sentados en el telar, nos gusta tejer, hacer correr la lanzadera por entre los hilos tensados de la máquina. Repetir, una y otra vez, el movimiento certero, de derecha a izquierda y viceversa, de las manos que escriben el dibujo de la tela.

Hace muchos decenios que condenamos a la mujer a la repetición imposible del gesto, a la infinita condición de muda del sentido, a ser la criatura que se desdice de su palabra borrándola cada vez que la escribía, borrándola en su ceguera. Allí, abandonada al vaivén improductivo de la mirada, dejamos a Penélope y decidimos asignarnos para nosotros el camino del retorno y del habla que discurre tejiendo el sentido. Desde que somos historia ha sido así: sentados en el banco de los hilos polvorientos, creemos escribir lo que puede verse y tocarse, y no hacemos más que, azarosamente, imaginar un espacio de redes entrecruzadas siempre cambiantes, paralelas a nuestra voluntad y relacionadas con otras superficies hechas por otras manos. En lugar de textos emitimos ecos de sentido cruzándose caminos imprevisibles. Creíamos conocer sustancias y apartamos de ellas a las mujeres. Resultaron ser voces del pasado, desgastadas e inservibles.

Empezamos a comprender, desde Charles Sanders Peirce (Zeman, 1977; Tordera, 1978; Ponzio, 1988) o Mijail Bajtín (Bachtin, 1977), por 
citar sólo dos puntos de referencia, que las cosas no pueden definirse y controlarse desde ellas mismas, sino que tenemos que recurrir a otras cosas, a otros mundos, para poderlas situar en el cosmos. Si una palabra se mira el ombligo, es ciega y no dice nada del sentido. De hecho, aunque su voz deje oír al otro que escucha, siempre será un decir accidental. La cosas podrían haber sido de otro modo, nos decía Walter Benjamin. La mano que traza el camino de la lanzadera, mano encontrada, se ve a sí misma impotente para decidir el sentido del color.

Esta reflexión quiere situarse debajo del tejido y soportar su peso y su materialidad. Nos distanciamos con Lotman de las tesis bivalentes y deterministas y asumimos el carácter azaroso del sentido, sus múltiples caras, su imposible aprehensión. Quisiéramos dar una vuelta de tuerca más al excelente trabajo sobre semiología de la cultura del ruso de Tartu, centrándonos en el análisis del texto fílmico, otro campo al cual se acercó también el profesor de Estonia. Nos atreveríamos quizás a proponer nuestro concepto formal de sentido y aplicarlo a unas breves secuencias del cine cifesiano. Tendremos en cuenta el concepto bajtiniano y lotmaniano de texto e intentaremos definir lo que será para nosotros ficción y modelos de representación.

El arte primero y la estética después han sufrido muchas transformaciones y reclasificaciones desde que Penélope jugaba al tiempo inconcluso de la obra hueca, pero no hemos salido todavía de Grecia. Quizás estemos de vuelta al Mito entre tanto canto postmoderno. Se tratará aquí de seguir un curso al azar y tejer un sentido de traducción dudosa, como cualquier otro dibujo hecho de telas multicolores.

Lo que marcará de una manera insistente nuestra mirada sobre el signo «Cifesa» será la voluntad de encontrar en la tecnología allí utilizada el mecanismo de destrucción que permitirá desvelar la trampa de cualquier narración, aleceiar el «se»: desplazando al se de su lugar presencial, sacarlo de su cotidianeidad; traerlo a una posición ética previa a su constitución, colocarlo en el lugar de la ficción; y devolverlo cambiado a esa paz inestable cargada de extrañeza, empezar la hélice de nuevo. Porque, si hay alguna cosa que define el modo de representación del constructo «Cifesa», es la voluntad de narrar.

Toda narración cuenta en pasado, o en presente, siguiendo una estructura lineal de principio, nudo y desenlace, la historia de unos personajes (quién), en un lugar (dónde) y un tiempo (cuándo), que hacen cosas (qué), con un porqué y un cómo laterales. Todo ello aderezado de pausas audiovisuales para que el espectador, el interpretante, tenga el 
tiempo necesario y el aliento suficiente para coser el sentido que de aquella historia se deriva. El espectador de 1936 y el espectador de 1995 se diferencian, sobre todo, por el tejido que los construye. Este tejido está formado por todos los cruces posibles que atraviesan la diferencia entre lo real y la ficción, entre la posibilidad de verter en la ficción la carencia inherente a lo real. Entendemos, pues, por real la extrañeza que produce lo cotidiano. Entendemos por ficción el cajón donde guardamos esa extrañeza. En sentido estricto, por lo tanto, real no hay nada dentro de la narración, en el discurso. El mundo de las construcciones discursivas funciona siguiendo este esquema:

\section{cotidiano-extraño-ficción-cotidiano}

siguiendo un proceso de retroalimentación que no se rompe mientras seamos capaces de mantenernos en el medio, en el medium. Cifesa narra, pues, ofreciendo lo cotidiano al espectador del ' 36 , de manera que lo extraño pueda verterse en la ficción allí representada, y poder volver a lo cotidiano catárticamente limpio de culpa. Al espectador del '95 aquella cotidianeidad no debería decirle gran cosa, pero no es así. Entre Cifesa y Almodóvar apenas hay un soplo de historia.

No hay ni ha habido nunca posibilidad para el hombre de un conocimiento directo del mundo. El hombre está condenado a conocer mediante el lenguaje. El hombre interpone entre él (que ya es lenguaje) y el mundo las palabras, que también lo configuran. El hombre, desde que es hombre, es mensajero (hermeneuta). Primero, durante la infancia, a través de otros hombres, de una manera absoluta y que conocemos como pre-estadio del espejo, en que todavía no se ha separado del yo, verdadera entelequia. Después, mayor, viéndose a él mismo alejado de sí, el tú. Y siempre, asediado por lo que le es extraño y no codifica si no es por medio de la ficción, el mecanismo que aquí llamaremos retroalimentación.

El mito seguramente servía para cerrar ese camino que completa el sentido en forma de ficción, sin la cual el abismo estaría servido. Por lo tanto, proponemos un modelo, quizás viejo: el sentido sería la acción de sacar de la identidad, a través de la ficción, aquello que nos resulta extraño en lo cotidiano. Puede que no haya otra manera racional de sacar afuera todo lo que no ha sido identificado y reconocido como propio. Este mecanismo funcionaba ya en los Mitos. El interpretante de aquel mundo disponía de piezas que eran intercambiables y reciclables.

En realidad, el mito del siglo XX ha sido y es la televisión, el lugar del sentido. Se ha avanzado muy rápidamente desde aquellos refugios 
del deseo llamados Cifesa y otros parecidos. Hemos llegado a las verdaderas tecnologías que permitirán un uso exclusivo y personalizado de la información, con la telemática como telón de fondo provisional. Ahora Dios ha muerto y ya no son necesarias las salas de cine. Muy pronto el espectador, el interpretante, pasará a ser el autor explícito de su sentido y el onanismo estará consumado: lo que comentaremos entre nosotros serán las personalísimas e inintercambiables experiencias de sentido de cada uno. Puede que el hombre, como lo hemos concebido desde hace poco más de doscientos años, esté a punto de perecer y borrarse, como diría Foucault (1990: 375): «como en los límites del mar un rostro de arena».

\section{El telar pronto será un pajar.}

Cifesa, pues, se sitúa a caballo entre el Mito y el onanistrón cyburgués, y es, desde este punto de vista, un elemento arqueológico, como casi todo el cine que conocemos en la actualidad, y la televisión y los periódicos, y las maneras que tenemos de comunicarnos, que conviene valorar y estudiar en sus justos términos: Cifesa es uno de los primeros significantes que ayudaron a entrar ligeramente en la postmodernidad. En este sentido, también, se puede decir que ha ayudado a convertir el banco de madera del telar en paja húmeda.

La historia de los modelos de representación podría asociarse a una historia de la estética y podríamos tratarla de dos maneras distintas: como la historia de los hombres que los crearon o como la historia de las problemáticas que se derivaron de aquélla.

Cifesa, de los grandes períodos en que puede dividirse la historia, formaría parte de la contemporaneidad. Estos períodos son: Antiguiedad, hasta Plotino; Edad Media, desde San Agustín hasta Dante; Época Moderna, desde Petrarca hasta principios del XX; y el siglo XX como representante de la Contemporaneidad. Hay dos tiempos no historiados todavía: el mítico, porque no contiene textos escritos conocidos (anteriores a la Odisea), y la postmodernidad, porque sus imágenes tienden a autodestruirse. Nuestra intención sería aplicar una técnica mítica, como podría ser el bricolaje, al análisis de los textos fílmicos cifesianos, que son casi postmodernos.

Si sentido era la acción de sacar de la identidad, a través de la ficción, aquéllo que nos resultaba extraño en lo cotidiano, modelo de representación institucional, porque no creemos que haya otro - siempre se representa desde la Institución o no se representa desde el vacío-, será, precisamente, el Arte; esto es, la ficción. 
Si aceptamos que las clasificaciones del arte se adecuan a los cambios que a lo largo de la historia se han producido y obedecen a las necesidades que en cada tiempo han creado las clases dirigentes, hemos de aceptar que toda clasificación es interesada y nada sustancial por lo que afecta a las clases no dirigentes. Cualquier Modelo de Representación está, pues, sujeto a los intereses y necesidades de una función -funcionalidad- marcada por aquéllos que los crearon.

Pero volvamos a nuestra definición de Modelo de Representación, que también será interesada. Es, decíamos, la puesta en marcha de unos mecanismos de Identificación que encierran lo extraño vivido en lo cotidiano y escapan gracias a la ficción. El Modelo de Representación es el canal mediante el cual el sentido vuelve al emisor. Cualquier proceso de comunicación funcionaría así, sólo que el de la ficción es un superproceso o estructura de lo cotidiano:

\section{COTIDIANO — EXTRAÑO — FICCIÓN}

Se produce un mecanismo de ósmosis de doble dirección: por una parte lo cotidiano fluye hacia lo extraño y esto a su vez hacia la ficción. Desde aquí se inicia el proceso de retroalimentación de lo cotidiano, recodificado y reidentificado lo que parecía alejado de nosotros. A este proceso lo llamaremos sentido.

El concepto de texto de Iurij M. Lotman (1985: 265) restituye la interpretación etimológica de los antiguos y se relaciona con lo dicho anteriormente. Es un concepto muy antiguo, efectivamente, que considera el texto como algo dinámico e interactivo, que presupone que las cosas no pueden ser definidas con respecto a su ombligo sino que se han de relacionar con otras cosas, multiplicidad de ellas, de acuerdo con Bateson (1984:52), de forma y manera que cada paso en el conocimiento humano sería una pasada de la lanzadera (Elkana, 1981: 157-158).

El modo de relacionarse con el extranjero supone la mediación de una lengua común que permite la interiorización, la reidentificación, de lo ajeno, según Lotman. La desintegración y posterior reorganización del texto recibido por el otro permite a la Identidad reafirmarse en sus posiciones. Su autocomplacencia en lo mismo.

Donde Lotman ve el diálogo entre colectivos extraños, nosotros aplicamos la recomposición del sentido desde el lugar del interpretante individual. Las mediaciones que utiliza una cultura para dialogar serían las ficciones con que el interpretante resume e interioriza lo extraño. La lengua común que ambas culturas, extrañas entre sí, con- 
sienten en crear para entenderse, sería el lugar que nosotros llamamos extraño. El sentido, precisamente, sería el momento en que lo extraño, lo extranjero, es reasumido como propio en el mundo de la Identidad. En cualquier caso, se trate de diálogo entre culturas distintas o de la escucha de un texto por parte de un espectador, se saca fuera de sí, abriendo lo mismo y lo cotidiano, lo que de extraño hay en nosotros mismos y se deposita en la ficción, para luego volver a la propia Identidad más complacido.

Para Lotman, el diálogo se produce entre dos conciencias que dejan de ser, provisionalmente, Identidades para así poderse reorganizar mutuamente. Cuando se deja de ser Identidad y de estar en lo Mismo, aparece lo extraño que es el Otro y proyectamos en la ficción la recomposición de aquélla. Para Bajtín (Bajtín, 1977) la vida misma del texto huye de conciencias internas y escapa a la aprehensión de éstas. Su concepto de texto es más barthesiano, a nuestro entender, que lotmaniano y deja que en él habite un resto indescifrable de sentido. En realidad, si la operación del sentido se produce en la brecha de lo mismo, la propia fisura impedirá la recomposición Idéntica de lo cotidiano. Ese organismo dinámico e interactivo que es el texto deja escapar por entre sus hilos gotas de nada que huelen a blanco. Esa pesada sombra de huecos sin mano que la dibuje también es el sentido por encontrar. Pero es el camino por donde habrán de encontrarse aquellos mismos rotos en mil pedazos que llamamos aquí extraños. Por lo demás, el sentido, otra vez, será la operación osmótica del paso de la Identidad a la Diferencia habiendo soportado el peso de lo material sin nombre, blancas razones, en el oscuro y húmedo espacio que media entre el texto y el suelo del telar.

El lugar del sentido ya no será la razón o lo cotidiano con todas sus leyes, sino la ficción, que permite que dos conciencias alejadas en el tiempo histórico se acerquen de una manera definitiva al verter lo extraño, lo extranjero, en la representación.

\section{APLICACIÓN PRÁCTICA}

Pero veamos cómo actúa este mecanismo en nosotros, espectadores de un texto fílmico de los años treinta. Se trata de la secuencia del juicio por hurto de jamones de la película Morena Clara (Florián Rey, Cifesa: 1936). 
Se trata de un espacio que se representa a sí mismo mediante códigos gráficos. Leemos la citación de un juicio, vista pública, y nos encontramos allí. Estamos en la sala del tribunal. Trini, que así se llama la presunta culpable, habla animadamente con alguien del público: se diría que se encuentra como en casa. El hombre que la acompaña en el banco de los acusados se siente un poco más incómodo. Tratará de aproximarse a la ley; intuye su peso. La mujer, en cambio, parece molestar a conciencia al juez.

Aparecen imágenes alternativas de los presentes en la sala: tribunal, defensora, acusador y público. Se respeta el espacio en el montaje y el espectador es capaz de rehacerlo mentalmente. Los planos y contraplanos entre el fiscal y la acusada muestran a ésta dispuesta a contestar con gesto excedido. El tribunal le llama la atención, pero no se detiene de inmediato. El hombre acusado, por su parte, es mucho más cuidadoso y comedido. Quizás conviene que nos preguntemos por qué se le otorga la posibilidad del gesto exagerado a la mujer y se le niega al hombre. $\mathrm{O}$, dicho de otro modo, ¿qué hay de menos valioso en la palabra de la mujer para que pueda ser dicha así y, sin embargo, no valer nada? ¿Por qué esa distorsión, ese desplazamiento, del centro del discurso? La respuesta parece evidente y está representada aquí magistralmente. La mujer, delante de la justicia, ni humana ni divina, pero también, sino la de los hombres con marca sexual, que viene a ser lo mismo, puede y debe exceder su gesto porque tiene menos valor y se escucha menos, aunque se oiga más. No es lo mismo, ya lo saben ustedes bien, callar que estar callado. Se valora menos lo segundo, el participio, porque está más acabado, más usado; un infinitivo tiene toda la vida por delante. Trini parece un participio del verbo hablar desparramado en la sala del juicio. Ella es hablada por nosotros en su mudez. Por eso puede exagerar su gesto y su voz, porque se lee disminuido y se valora menos y está ya en el suelo.

Ahora tiene la defensa la palabra, que es breve, porque es femenina.

El ujier llama a alguien que no llega. Aquí hay un error de raccord. Parece que llame a la acusada, pero no es el caso. Comienza el monólogo del fiscal dirigiéndose a la sala. Primero al tribunal, después directamente a la acusada, que lo mira con los ojos unas veces divertidos y otras tristes. ¿ Qué ha sucedido con la seducción? Parecería que la condenada al silencio, a la exclusión - sus interferencias al discurso del fiscal van rebajándose hasta desaparecer- pasa del momento del «panopticon» - las palabras del fiscal la paralizan y la dejan en una total exposición - al del arrepentimiento: parece la reclamación 
desesperada de la voz que se sabe muda: el detenido, el loco, pide al fiscal volver a ser escuchado.

La larga perorata del fiscal parece preocupar, finalmente, a los acusados. La desrazón acaba por escuchar a la razón y se deja prender. El eco lejano de la risotada envuelta de muerte ya no suena. Las señales mágicas que comportaba han sido eliminadas. Al loco ya no le queda nada más que permanecer en el silencio, toda vez que la razón se ha ocupado de él, ocupándolo y tragándoselo en un moviento doble que cose su propia carencia. La razón es violencia de exclusión.

Ahora tiene el turno de réplica la abogada. ¿Por qué han elegido a una mujer para defenderlos? Tiene la palabra el modelo de representación. Habla y mira hacia el fiscal; otras veces hacia el tribunal. Pero lo tenemos que suponer, no hay ningún contraplano que nos lo haga narrativamente cierto; sólo es una suposición nuestra por el lugar que ocupa cada uno de ellos en el espacio imaginario de la sala. Es evidente que la necesidad de la defensora de mirar al fiscal y así reclamar su mirada, que no sabemos si llega porque el montaje no nos lo dice, nos muestra la doble posición de fuerza fiscal, que es hombre y acusador, y no necesita devolver la mirada y otorgar la palabra a la defensa, excepto al final y de una manera reducida. La mujer habla más desde el sentimiento que desde la razón, y en este hablar o ser hablada su discurso se diluye en el vacío porque no obtiene respuesta.

El hecho de que la defensa sea mujer se explicaría, a nuestro entender, por dos motivos. Por una parte permite a Florián Rey y a Cifesa defender una posición de los gitanos desde el gesto excedido y poco valioso de las mujeres y no comprometerse. La defensa es de tipo humanitario y no clasista; de amor al prójimo y no reivindicativa de una economía particular; de limosna y no discursiva; astrológica y espiritual, nada materialista ni históricamente razonada. Mientras tanto, el fiscal ha basado sus ataques contra una manera de vivir que hace del ingenio su arma más poderosa para deslegitimarla y traerla al lugar que él domina: la palabra. La abogada quiere convertir mediante la redención a los gitanos y transformarlos en materiales útiles a la sociedad: ponerlos a trabajar, en una palabra.

El segundo motivo, o segunda justificación del hecho mujer-abogada, consistiría en que la oposición del fiscal sea, de entrada, más fuerte que la de su compañera de oficio. Esto es, justificar desde la base de la ideología del film quién tiene razón y quién no. Si la defensa hubiese sido hombre, sólo por coherencia interna del sistema 
machista, el fiscal se hubiese tenido que ganar más razonadamente su razón y argumentarla más. Un hombre no puede ni debe tapar la boca de otro hombre porque sí; ha de justificarlo. El montaje nos hubiera parecido entonces absolutamente impresentable. Cómo es posible, nos habríamos preguntado, que se ignore de un modo tan evidente la parte que defiende. $Y$ aún, cómo es posible que se defienda tan mal. En cambio, al tratarse de una mujer, desde el hueco cualquier eco de luz.

Para un espectador del ' 36 no sería demasiado habitual encontrarse con una mujer abogada defendiendo a otra mujer gitana. Y, de hecho, la defensa, no está representada en la pantalla porque su mirada ha sido borrada, pero el mecanismo funciona:

\section{Cotidiano - Extrañeza- Ficción}

Que la mujer del '36 quisiese hablar y decir, resultaría extraño si su mirada no se redujera sólamente a la gracia y al salero de la gitana. La ficción del film, el modelo de representación, es capaz de reasumir esta extrañeza y reconducir el sentido, porque en realidad, decíamos, la abogada no llega a existir «realmente».

La cotidianeidad del ' 95 permite pensar en una mujer que actúe de abogada y no nos produce ningún sentimiento extraño. Lo extraño aparece al comprobar que, efectivamente, esta mujer no está narrativamente inserta en el discurso, pero lo atribuimos al hecho de estar delante de una ficción del '36. Pero en ambos casos la mujer ha sido borrada del texto artístico y como entidad productora de sentido no existe. Una vez más, el diálogo, el banco de madera del telar ha sido reservado a los hombres.

La ficción es en cualquier caso lo que permite pensar al espectador del '36 que «bueno, es mujer». Y al espectador del '95: «hombre, es que es una película del '36». Y es así como estas dos comunidades de espectadores, extrañas entre sí, establecen un diálogo común, toda vez que se han desprendido, aparentemente, de su identidad propia, y pueden comunicarse y producir - reproducir - un sentido, aparentemente, nuevo.

El círculo se cierra, eso sí, habiendo crecido un poco más lo cotidiano o idéntico: lo simétrico. El sentido es, en definitiva, la reducción de lo otro a lo mismo bajo la apariencia de un diálogo común que nunca se produce, porque en la ficción no hay acuerdos, hay goce. Por eso el sentido no está del lugar de la razón, del $\operatorname{logos}$, sino al otro lado, debajo del texto. Eso es lo que venimos repitiendo insistentemente: 
tejer y narrar lo cotidiano como si eso fuese ser el hacedor del mundo es una apariencia que se manifiesta real en lo extraño, y una paradoja que se resuelve en la ficción.

Si volvemos atrás, hacia la secuencia que comentábamos, observamos que aparece como familiar al espectador del '36 la manera de expresarse de Trini, con su gracia y su salero. Incluso, si estuviera representada, el hilo de voz de la abogada. Lo extraño pasaría a ser el tono y los gestos del fiscal, pero es lo que los hace reflexionar a los espectadores contemporáneos del film, y dudar de la conveniencia de un comportamiento delictivo. Esa duda se resuelve de inmediato en la ficción, lugar del sentido: aunque el fiscal impresione con su perorata y su razón, porque es él el que la tiene, moral y narrativamente, ahora en la fícción se la dan a los gitanos, tan graciosos. Los gitanos, después de ver el film son más gitanos que antes para un espectador medio. El fiscal es más fiscal y la razón, más gruesa: lo cotidiano se ha crecido, sin duda. Ese es el mecanismo de retroalimentación de que hablábamos al principio.

En otro lugar (Franco, 1996) decíamos que la ficción es el residuo de lo público, y lo es en el sentido de que nos permite ser lo que de otro modo nos estaría prohibido: el goce público está reservado a unos pocos. Digamos que en la pantalla, en la ficción, es donde cosemos el sentido que después en lo cotidiano nos permite permitir al otro ser.

Decía Lotman (1979: 10):

El cine se parece al mundo que vemos. El aumento del parecido es la medida que determina la evolución del cine como arte. Pero ese parecido es insidioso como las palabras del idioma ajeno semejantes a la del propio. Así surge la comprensión aparente, no verdadera. Sólo cuando se comprende el lenguaje del cine se ve que no se trata de una copia servil, mecánica de la realidad, sino de una recreación activa donde el parecido y la disimilitud forman un sólo proceso de conocimiento, proceso, a veces dramático, de la realidad.

«Lo otro se disfraza de propio»; aquí tenemos condensado el mecanismo de recreación de sentido. El interpretante se disfraza y el texto también. Hay un acuerdo no escrito que los escribe a ambos: la permanencia en lo mismo. Lo otro se disfraza de propio para convencer de su verdad al otro que escucha, que a su vez se ha disfrazado de otro para poder escuchar. Lo mismo, lo idéntico es mudo y sordo y posee la razón; es la realidad cotidiana, ciega y gris en su mismidad mediocre. La salida de lo mismo se produce en la fisura de lo extraño y el 
diálogo aparente, no verdadero pero sí real, - ¿cúal sería la diferencia?-, tiene lugar en la ficción del texto artístico. Y del otro también.

En otro sitio de Lotman (1979: 21) leemos:

$\mathrm{El}$ arte no reproduce simplemente el mundo con el automatismo inerte del espejo: él convierte las imágenes del mundo en signos, él llena el mundo de significados.

Ese trabajo de hacedor del sentido del arte en general, y del cine en particular, es posible gracias al desdoblamiento que sufre lo cotidiano en lo extraño y a su posterior recomposición en la ficción, en el arte. Es posible gracias a que el interpretante, y también el texto, la ficción, se desdoblan en dos para encontrarse de nuevo en lo cotidiano crecido. La razón se redobla mediante este mecanismo de reducción de lo otro a lo propio. Lo roto en la pantalla se deja interpretar por el ciego que escucha. En la vida real no hay segmentación posible y el ciego se convierte en vidente. En lo cotidiano las expectativas no son defraudadas nunca; si algo no es o no sale como esperábamos, no se convierte para nosotros en signo de nada: se tratará sólo de un cálculo erróneo, de una desgracia quizás, pero no de un significado nada oculto sino bien visible. En la ficción, si se rompen las expectativas, se produce significado. De la secuencia que hemos comentado, lo roto en la pantalla, lo que produce significado para el espectador del ' 36 , es el hecho de que sea mujer quien defiende a la gitana. Esa fisura de luz es leída y reconducida por el interpretante, abierto a su vez por el doble movimiento de sutura de que hablábamos más arriba: por el carácter sentimental de la defensa, poco razonado, y por el hecho de que su presencia se diluye en el montaje como si de un fastasma se tratase. Para el espectador del '95 la fisura fantasmática es, precisamente, la no-presencia diegética de la mujer abogada en el discurso narrativo del film. Esta fisura se cerrará atribuyéndolo al carácter arcaico de la película y sus planteamientos no clasistas. El sentido último no ha cambiado en nada: la mujer no está presente en el telar.

Todo lo que vemos en la pantalla significa por esa capacidad del texto artístico de anular la redundancia y aumentar la información; por esa capacidad de ser predecible e impredecible. Por ser un doble. Como el interpretante que lo escucha en su ceguera. En el texto artístico «lo igual se vuelve diferente y viceversa», según Lotman (1979: 82); es una lucha constante entre lo cotidiano, con todas sus leyes y normas, y lo extraño y sus transgresiones. Lucha que se resuelve, 
decíamos, en la ficción. Ese aceptar las normas y rechazarlas, esa ruptura de lo lineal cotidiano es el elemento significante: el cruce de lo recto roto en retículas: el texto.

Las manos del telar son manos encontradas, coros polifónicos que prueban a decir su voz en la marea sígnica del mundo. La misma organicidad dinámica del texto artístico nos impide reducirlo a cosa acabada. Otras manos, otras voces, otros Ulises llegarán en el momento preciso para evitar que Penélope finalice su texto. No es ya una cuestión de poder, solamente; es que lo Mismo no puede permitir tejer al Otro si antes él no se diluye en lo fantasmático de la ficción. Los que esperan su turno ya son reyes en su Identidad. Lo que quieren ocupar es al otro «mujer» para hablarla desde su interior. Desde esa oscura extraneza se escribe el mundo de lo cotidiano, y no entre aquellas series serias, opuestas, del inicio, ni desde ese yo cojo, sino desde el ser abierto de par en par al goce del texto.

\section{Referencias bibliográficas}

Bachtin, M. M. (1976). «Problema Teksta». En Voprosy literatury. 10.

[Trad. it. (1977). «Il problema del testo». En Michail Bachtin, Augusto Ponzio (ed.), Bari: Dedalo].

BARTHES, Roland (1973). Le Plaisir du text. París: Seuil.

- (1975). Roland Barthes par Roland Barthes. París: Seuil.

- (1977). Fragments d'un discours amoreaux. París: Seuil.

- (1981). Le grain de la voix. Entretiens 1962-1980. París: Seuil.

- (1986). Lo obvio y lo obtuso. Barcelona: Paidós.

- (1987). El susurro del lenguaje. Barcelona: Paidós.

BAteson, G. (1979). Mind and Nature. A necessary Unity.

[Trad. it. (1984). Mente e Natura. Milano: Adelphi].

BODEL, Remo (1986). «Foucault: pouvoir, politique et mâtrese de soi». Critique 471-472, 898-917.

DELOOZ, Thierry. (1986). «Après Foucault: parler, dire, penser». Les Études Philosophiques, octubre-diciembre, 441-450.

ElKANA, Y. (1980). «Of Cunning Reason». En Merton Festschrift. New York:

Academy of Science. [Trad. it. (1981). «La ragione astuta». En La nuova ragione, Paolo Rossi (ed.), Bologna: Il Mulino].

FouCAult, Michel (1954). Maladie mentale et personnalité. París: Presses Universitaires de France.

- (1961). Folie et déraison. Histoire de la folie à l'âge classique. París: Plon. 
- (1963). Naissance de la clinique. Une archéologie du regard médical. París: Presses Universitaires de France.

- (1966). Les mots et les choses. Une archéologie des sciences humaines. París: Gallimard. [Trad. esp. (1990). Las palabras y las cosas. México: Siglo XXI].

- (1969). L'archéologie du savoir. París: Gallimard.

- (1970). L'ordre du discours. París: Gallimard.

- (1973). Ceci n'est pas une pipe. Montpeller: Fata Morgana.

- (1975). Surveiller et punir. Naissance de la prision. París: Gallimard.

- (1976). La volonté du savoir, histoire de la sexualité. París: Gallimard, vol. 1.

- (1984a). L'usage des plaisirs, histoire de la sexualité. París: Gallimard, vol. 2.

- (1984b). Le souci de soi, histoire de la sexualité. París: Gallimard, vol. 3.

FrANCO I Giner, J. (1996). «La ficción como residuo de lo público». En Actas del VI Congreso Internacional de la Asociación Española de Semiótica, Investigaciones Semióticas VI, 681-683. Murcia: Universidad de Murcia. GonZÁleZ REQuenA, Jesús (1981). «Para la definición de una teoría del texto artístico». En Actas del I Congreso Internacional de la Asociación Española de Semiótica, 44-164. Madrid: CSIC.

LÉviNAS, Emmanuel (1961). Totalité et Infini. La Haya: Nijhoff.

- (1987). Hors Sujet. Montpeller: Fata Morgana.

LOTMAN, I. (1979). Estética y semiótica del cine. Barcelona: Gustavo Gili. - (1985). La semiosfera.

PeIrCE, Ch. S. (1987). Obra lógico-semiótica. Armando Sercovich (ed.). Madrid: Taurus. [Para edición de textos.]

PONZIO, Augusto (1982). Spostamenti. (Percorsi e discorsi sul segno). Bari: Adriatica.

- (1983a). Lo spreco dei significanti. (L'eros, la morte, la scrittura). Bari: Adriatica.

- (1983b). Tra linguaggio e letteratura. Bari: Adriatica.

- (1988). Rossi-Landi e la filosofia del linguaggio. Bari: Adriatica.

- (1989). Soggetto e alterità. (Da Lévinas a Lévinas). Bari: Adriatica.

- (1990). Il filosofo e la tartaruga. Scritti (1983-1988). Ravenna: Longo.

SCHÜRMANN, Reiner (1986). «Se constituer soi-même comme sujet anarchique». Les Études Philosophiques, octubre-diciembre, 451-471.

TALENS, J., CompanY, J.M. y HeRnÁNDEZ, E.V. (1985). «Lenguaje literario y producción de sentido». En Métodos de estudio de la obra literaria, J.M. Díez Borque (ed.), 523-551. Madrid: Taurus.

TORdera, A. (1978). Hacia una Semiótica Pragmática. El signo en Ch. S. Peirce. València: Fernando Torres.

Zeman, J.J. (1977). «Peirce's Theory of Signs». En A Perfusion of Signs, Th. A. Sebeok (ed.), 22-39. Bloomington: Indiana University Press. 